\title{
Viewpoint
}

\section{Addressing conflicting views on wearing of facemask by the public to combat COVID-19: experiences from the East Asia region}

\author{
Benjamin TY Chan' \\ ${ }^{1}$ Li Ka Shing School of Professional and Continuing Education, The Open University of Hong Kong, Ho Man Tin, Hong Kong \\ Keywords: novel coronavirus, facemask, covid-19, pandemic, east asia \\ https://doi.org/10.29392/001c.13066
}

\section{Journal of Global Health Reports}

Vol. 4, 2020

\begin{abstract}
The practice of wearing a mask to prevent new coronavirus infection has caught media attention and raised concern in some quarters of the medical community. This paper looks into the issue's socio-cultural background and the science of droplet transmission to seek for answers, with a call for the WHO to take into account in its interim guidance document the experiences of East Asian countries when further refining its recommendation on masking in the community.
\end{abstract}

Shortly after the beginning of the COVID-19 outbreak in late January, the WHO issued a set of advice on the use of masks which states that healthy individuals without respiratory symptoms should not wear a mask. ${ }^{1}$ This interim guidance was adopted in guidelines of health authorities around the world. As the epidemic progressed in China, the discovery of large numbers of confirmed cases to be asymptomatic carriers before being hospitalised had seriously undermined the WHO interim guidance's validity. ${ }^{2}$ To date, China has enforced a stringent advisory on wearing of mask by everyone in the presence of others as a form of preventive strategy. ${ }^{3}$ Other East Asian countries and regions have taken up masking in public either mandatorily (for many ASEAN countries, Taiwan and Macau) or voluntarily (Hong Kong, South Korea, Japan). Several articles in mainstream medical journals had questioned the WHO interim guidance and called for clearer advice to be made to the public on mass masking. ${ }^{4-6}$ There was also disquiet within the medical communities of East Asia on the issue, sometimes showing a divided view between medical professionals and their national health authorities before the matter was eventually settled by government's directive for compulsory masking as exemplified in the case of Singapore. ${ }^{7,8}$

\section{MASK WEARING ANXIETY OR RISK AWARENESS}

When confronted with the choice of whether to wear a mask to avoid being infected with the new coronavirus, there is evidently a big difference in attitude between the two epicentres of the pandemic, China and Western Europe/United States. The governments and media in Western Europe and America generally discourage the practice of masking by healthy people, whilst in China, the issue of masking finds no dispute at all from the government down to its citizens. Other neighbouring areas - Hong Kong, South Korea, Taiwan - have in the very early phase of the pandemic witnessed a large number of their citizens wearing it by themselves, and governments in these places have to take swift actions to resolve the mask supply crisis through rationing and boosting of local productions. Some in the Western me- dia and a few psychology academics have interpreted the preference for mask wearing in East Asia as a cultural habit or a psychologically motivated act prompted by the need to gain personal control over the virus, so as to give the wearer supposed protection akin to a 'superstitious belief'. They also believed that mass masking could have negative consequences in drumming up anxiety levels especially when people feel being left out by others who were wearing one. ${ }^{9}$ In sharp contrast, views from China generally take the 'noneed-to-wear-mask advice' to be a serious threat against global disease prevention and control. This opposing view cites mask famine and also the cultural habits of the West which equate mask wearing with being sick as what really impedes the acceptance of masking as a protective measure. ${ }^{10}$ The head of the Chinese CDC openly made his call for people in Europe and US to wear a mask saying that otherwise it would be a mistake because of the virus' transmission route via droplets. ${ }^{11}$

Given the cultural habits thesis is used by both sides to explain what they regard to be the main reason for favouring or discouraging facemask usage, reference to a global survey on how much respondents know about the new coronavirus and how much they think it is a threat to public health can help shed some light on the issue. The international survey undertaken by London-based YouGov reported that familiarity with coronavirus was generally higher in Asia and the Middle East than it was in Europe and the US. At the same time, in Europe and the US, people were far less likely to see coronavirus as a major threat to their home country and other places in the world. ${ }^{12}$ These findings point to reasons beyond culture, and that an understanding about the new coronavirus probably through previous encounters with SARS in 2003, may have heightened risk awareness in China and other parts of East Asia about COVID-19, that in turn influences their populations to consciously take up precautionary measures including masking.

This then brings us to the sociological literature that looks at masking in East Asian societies as typified by Japan. ${ }^{13}$ Sociologists who theorises the issue based on risk 
society and individualisation of health argues about discarding the old modernity view of collectivist norm-regulated mask wearing behaviour in favour of a new modernity outlook based on individuals taking responsible actions to mitigate public health risks. Such conceptualisation which eschews the cultural factor can be a useful explanation as to why some Western societies such as the Czechs manage to quickly adapt masking upon realising the benefits demonstrated in East Asia. One could probably say that Czech citizen's risk perception and management, under the steer of their government which engaged in policy learning from East Asia, notably Taiwan ${ }^{14}$, had synchronised with advanced East Asian societies and which was not dependent on a radical change of Western cultural norms to accept masking within that short period of time. This is only possible likely because communities in advanced East Asian societies (Japan, South Korea, Taiwan, Hong Kong) and the Czech Republic are characterised by the same kind of attitudes towards risk as they share a common denominator new modernity

\section{RECOURSE TO SCIENCE}

Moving past cultural assumptions about masking, the scientific discussion behind its effectiveness is equally unsettling because the WHO continues to uphold its position about the lack of credible evidence in the latest update to the interim guidance document made on April 6. ${ }^{1}$ It mentions thus: "However, there is currently no evidence that wearing a mask (whether medical or other types) by healthy persons in the wider community setting, including universal community masking, can prevent them from infection with respiratory viruses, including COVID-19.” The said update, which is the $3^{\text {rd }}$ iteration since January, has reviewed a set of scientific evidences collected from past studies but omitted some critical studies that are equally relevant but supportive of masking. These include a Cochrane systematic review study that supports surgical mask to be consistently and comprehensively effective in reducing spread of respiratory viruses ${ }^{15}$; a recent observational study of a package of non-pharmaceutical intervention measures which include masking that has worked to contain COVID-19 and influenza ${ }^{16}$; and a non-randomised study showing face-mask usage can reduce virus shedding in respiratory droplets. ${ }^{17}$

Some medical experts even caution that using masks improperly could increase the risk of exposure to the virus. Alternative measures such as hand washing and not touching the face are generally recommended. Whilst the latter may appear sound in theory, research had shown the almost involuntary manner that subjects touched their faces, ${ }^{18}$ and which could render the advice difficult to follow in practice without putting on a facemask. The challenge of coming up with conclusive evidence of effectiveness is also difficult to resolve as any rigorous experiment would need to obtain ethical clearance. By deliberately exposing one randomised group to the virus unprotected, such study would almost certainly be prohibited to start in the first place. In one study undertaken to compare the efficacy of surgical mask and cloth mask in helping health care workers avoid contracting respiratory illness in a hospital context, the control group had to assume a 'normal practice with high proportion wearing a mask' instead of having a 'no mask' control group. ${ }^{19}$

Discussions about the validity of masking should take note that the main transmission mode of COVID-19 is through droplets, and the disposable type of surgical facemask represents the prevalent form used by the public. There has been a lot of mention about the size of the new coronavirus particle and the inability of the common 3-ply surgical facemask to filter it. This kind of uncritical assessment is neither helpful nor scientifically sound. Viruses mixed in saliva and other secretions can form wet droplets up to the size of 100 microns when expelled from the human body following a cough or sneeze. The wet droplets could land on a person, the ground or other surfaces. A surgical facemask has an outer liquid repelling layer and this first line of defense would be able to provide a barrier against droplets when they hit the wearer's face. An attenuated droplet is also less likely to disintegrate immediately upon impact into sizes smaller than 2 microns that the next layer of filter cannot intercept.

The size of the new coronavirus ( 0.12 micron) suggests that it surpasses the filtration capacity of the surgical facemask (2 microns). But this is not a persuasive point because only dried out viruses from droplets that remain airborne stay in their original sizes. ${ }^{20} \mathrm{~A}$ free floating collection of virus particles suspended in the air are naturally diluted in number and it would require a larger quantity of these droplet nuclei to make someone fall sick. It is also inconceivable to think of the filtration layer of the facemask as though it works as a sieve where viruses are pulled in by gravity. The use of facemask also protects the public from asymptomatic carriers of the new coronavirus who may otherwise show no respiratory symptoms at all and be presumed healthy. Besides, masking does not entail doing away with social distancing and handwashing measures which should altogether constitute the trio of preventive measures to stop COVID-19 infection. One school of thought from public health academics suggest that wearing a mask during the pandemic may serve as a signal to alert about the ongoing public health crisis. ${ }^{21}$ The heightened awareness could serve to induce compliance with mitigating behaviours such as washing hands and practicing social distancing. This is the approach adopted by most governments that require the public to put on a mask when taking public transport or shopping for essentials. In practice, it can be seen as a shared responsibility where the government mandates masking as a condition for lowering mobility restrictions and enterprises (shops, transport companies) help to enforce it by requiring customers and passengers to comply as a condition for providing services.

\section{TACKLING MASK SUPPLY DEFICITS}

The supply of facemasks is decidedly a thorny issue for governments as no affected countries and regions can claim to have enough stocks to satisfy both the needs of its medical personnel and the public. This was also the reason why political leaders had stood by the WHO's guidance that healthy people do not have to wear a mask so as to save supplies for health care workers, carers of infected persons 
and individuals showing respiratory symptoms. The effective supply of masks to the public goes beyond merely considering stocks but has to include setting up distribution networks, ensuring equity and affordability of access, timely replenishment of stocks, and enhancing local manufacturing capacity. The experience of the East Asia region suggests that countries with a well-developed electronic health record system and digital infrastructure are at an advantage. For example, Taiwan made use of its national health insurance record system as a database to devise a rationing system for purchase of initially 2 and later 3 adult masks per week at local pharmacies that also involved its postal system in the logistics operation. Crucial to the success of their mask rationing and purchase by real name through presentation of a national health insurance card is the strong technology backup provided by the government with assistance given by private technology companies, the IT community, and technology savvy volunteers.

As smooth as it eventually turned out to be, the setting up process required boosting of server capacity, switching to faster fibre-optic network, creation of blockchain enabled mask inventory system with stock tracking capability at the distribution end, and development of application programming interfaces (APIs) to enable the public to check mask supply levels in pharmacies. ${ }^{22}$ This successfully implemented initiative has been upgraded repeatedly to an online order purchasing system and also through automatic vending machines following the boosting of local production from less than 2 million to 15 million pieces a day, and the relaxation of supply to 9 masks per 2 weeks for adults. Elsewhere, a practical though low-tech approach was initiated by the University of Hong Kong Shenzhen Hospital to teach the public how to handcraft their own DIY mask from simple materials to counter the scarcity of supply. ${ }^{23}$ The South Korean Prime Minister had during the height of mask supply deficit urged citizens to employ re-usable cotton masks to partially overcome chronic shortage of disposable facemasks. ${ }^{24}$ The Japanese government distributed 2 re-usable cloth masks to every family when disposable face-masks were running out of stock. ${ }^{25}$ These lay prescriptions are not without grounds because a previous study of non-pharmaceutical interventions against pandemic influenza has suggested that all types of masks (respirators, surgical facemasks and home-made ones) are likely to decrease viral exposure and infection risk on a population level in spite of imperfect fit and imperfect adherence. ${ }^{26}$ Interestingly, the efficacy of home-made cotton masks was studied before by researchers who concluded that it could be used as a last resort to stop droplet transmission from infected persons with pandemic influenza when commercial masks could not be procured.$^{27}$ In stark contrast is the following statement from the WHO's interim guidance document explaining its stance on the type of mask: "The use of masks made of other materials (e.g., cotton fabric), also known as nonmedical masks, in the community setting has not been well evaluated. There is no current evidence to make a recommendation for or against their use in this setting". ${ }^{1}$

\section{FURTHER UPDATING WHO GUIDANCE ON USE OF MASKS IN THE COMMUNITY}

Experiences of the East Asia region show that using facemask to control spread of the new coronavirus has gained practical importance at the population level due to a generally better understanding of the disease. Risk awareness amongst populations in this region should not be conflated with their assumed cultural preferences for masking as the former is based on understanding whilst the latter rests on habits of practice. As the first wave of COVID-19 infections moderate in China and has been outnumbered significantly by subsequent waves in Europe, North-America, the Middle-East, and elsewhere in the world, health advisories should be adjusted accordingly to provide timely advice to the public based on lessons learnt from China and its proximate East Asian neighbours where the outcomes speak for themselves. $^{28,29}$

There is yet no published study on public reactions to masking especially about its impact on different segments in the community. The case of the expatriate community in Hong Kong is illustrative of the differences in habits between the majority mask-wearing Hongkongers and resident foreigners/local returnees from abroad, where the latter group is regarded as lax in observing social distancing rules and many of them do not put on a mask. ${ }^{30,31}$ The communal friction coincided with HK's second wave of coronavirus infection starting in mid-March caused by imported cases from Europe and North America. The press and public opinion had cried foul of the behaviour which was divisive within the expatriate circle itself and in the larger community when racial overtones were hinted. Nonetheless, the Hong Kong case is considered mild relative to Thailand which also has a significant Western expatriate community. The Thai Health Minister openly called for foreigners in the country who refused to wear a mask to be deported. ${ }^{32}$ In reality, many long-term resident expatriates in Hong Kong do take up masking voluntarily either as a show of solidarity or upon realising that they have to be considerate to others. In a highly individualist society like Hong Kong which is predominantly Chinese by demography but not demonstrating the same collectivist orientation as in China, any explanation of masking based on deference to norms (e.g. custom of courtesy, altruism) appear weak and the phenomenon can be benefitted by a sociological explanation that looks into the individual's perception and handling of risk. This kind of explanation makes sense because local Hongkongers and long-term foreign residents have converged on a common understanding of risk posed by the coronavirus and thus subscribe voluntarily to masking.

Certainly, there are rooms for further updating to the WHO interim guidance on use of facemask by presumably healthy people who may be pre-symptomatic carriers of the virus without themselves knowing it. The updated guidelines must clearly spell out those circumstances affecting the user, the physical environment, epidemic situation, and especially to advise about permissible alternatives to a disposable facemask at the present moment rather than relegating it to future research. Of the many possible exceptions that can justify mask usage as a preventive measure, the list may include the following: service personnel who 
are in close quarters to clients; passengers riding on mass public transport and elevators; participants attending gatherings and staff in workplaces where social distancing of 1 metre apart cannot be achieved; the public in cities and localities with a high population density where communityacquired infections cases have been confirmed and are rising.

In an epidemic of vast scale such as COVID-19 outbreak, a run on facemask is almost certain to happen and therefore alternatives to the disposable type of mask should be validated and recognized. Whilst the empirical evidence to support effectiveness of facemask usage in slowing spread of new coronavirus infections has yet to emerge, its delay should not discredit the conscious choice and active effort made by societies and communities in East Asia to contain the COVID-19 outbreak, and which has begun to permeate through parts of Central and Eastern Europe through grassroot initiated mask making. ${ }^{33}$ As of this writing, the Czech Republic, Slovak Republic, Austria, Lithuania, Poland, Ukraine, Bulgaria, Bosnia-Herzegovina, Slovenia have required mandatory masking in public whereas Western Europe, except Germany and parts of Italy, remains slow in setting similar policies. For policy makers in places yet to decide on whether to enforce mandatory masking in public places, it serves to remind them that public health after all is the art to deal with complexity and uncertainty, and an evidence base which may not be complete. ${ }^{34}$

\section{POSTSCRIPT REMARK}

The WHO has updated its interim guidance on the use of masks in the context of COVID-19 on 5 June 2020

\section{ARTICLE HISTORY}

Received 23 March

Accepted 17 May

Funding: None.

Authorship contributions: BTYC is the sole author of the manuscript.

Competing interests: The author has completed the Unified Competing Interest form at www.icmje.org/coi_disclosure.pdf (available upon request from the corresponding author) and declare no conflicts of interest.

\section{Correspondence to:}

Dr. Benjamin Tak-Yuen Chan

Li Ka Shing School of Professional and Continuing Education

The Open University of Hong Kong

30 Good Shepherd Street

Ho Man Tin, Hong Kong

btychan@ouhk.edu.hk

This is an open-access article distributed under the terms of the Creative Commons Attribution 4.0 International License (CCBY-4.0). View this license's legal deed at http://creativecommons.org/licenses/by/4.0 and legal code at http://creativecommons.org/licenses/by/4.0/legalcode for more information. 


\section{REFERENCES}

1. World Health Organization. Advice on the use of masks in the community, during home care and in healthcare settings in the context of the novel coronavirus(2019 nCoV) outbreak, Interim guidance first issued on 29 January 2020, updated on 19 March and 6 April. https://www.who.int/docs/default-sourc e/documents/advice-on-the-use-of-masks-2019-nco v.pdf. Accessed April 24, 2020.

2. Bai Y, Yao L, Wei T, et al. Presumed asymptomatic carrier transmission of COVID-19. JAMA. 2020;323(14):1406. doi:10.1001/jama.2020.2565

3. State Council of the People's Republic of China. State Council's tips on workplace COVID-19 prevention, control. http://english.www.gov.cn/news/ topnews/202003/05/content_WS5e60511bc6d0c201c2 cbd988.html. Accessed March 7, 2020.

4. Leung CC, Lam TH, Cheng KK. Mass masking in the COVID-19 epidemic: People need guidance. The Lancet. 2020;395(10228):945. doi:10.1016/s0140-673 $6(20) 30520-1$

5. Feng S, Shen C, Xia N, Song W, Fan M, Cowling BJ. Rational use of face masks in the COVID-19 pandemic. The Lancet Respiratory Medicine. 2020;8(5):434-436. doi:10.1016/s2213-2600(20)3013 $\underline{4-\mathrm{X}}$

6. Chan ALY, Leung CC, Lam TH, Cheng KK. To wear or not to wear: WHO's confusing guidance on masks in the COVID-19 pandemic. BMJ. https://blogs.bmj.co $\mathrm{m} /$ bmi/2020/03/11/whos-confusing-guidance-maskscovid-19-epidemic/. Published March 11, 2020. Accessed April 24, 2020.

7. Chia RG. Cleaning your phone is better at stopping the coronavirus than wearing a mask, MOH says. Business Insider 13. February 2020. https://webcach e.googleusercontent.com/search?q=cache:ZI9TDNbP B5MJ:https://www.businessinsider.sg/cleaning-yourphone-is-better-at-stopping-the-coronavirus-than-w earing-a-mask-moh-says-heres-the-correct-way-to-d $\underline{0-i t+\& c d=1 \& h l=z h-T W \& c t=c l n k \& g l=h k}$. Accessed March 7, 2020.

8. Government of Singapore. When should I wear a mask? Available from. https://www.gov.sg/article/whe n-should-i-wear-a-mask. Accessed April 24, 2020.

9. Oaklander M. Health experts are telling healthy people not to wear facemasks for coronavirus, so why are so many doing it. Times. https://time.com/579472 9/coronavirus-face-masks/. Published March 4, 2020. Accessed March 7, 2020.
10. Xu KY, Wan L. Shortage prevents Westerners from wearing facemasks, sparks wider epidemic concerns. Global Times. March 2020. https://www.globaltimes.c n/content/1181610.shtml. Accessed March 8, 2020.

11. Mai J. Coronavirus: Chinese scientist advises people in Europe, US to wear facemasks in public. South China Morning Post. https://www.scmp.com/ne ws/china/society/article/3077413/coronavirus-chines e-scientist-advises-people-europe-us-wear-face. Published March 28, 2020. Accessed April 24, 2020.

12. Smith M. How do attitudes to coronavirus differ across the world? . https://today.yougov.com/topics/i nternational/articles-reports/2020/02/17/global-attit udes-coronavirus-poll. Accessed March 8, 2020.

13. Burgess A, Horii M. Risk, ritual and health responsibilisation: Japan's 'safety blanket' of surgical facemask wearing. Sociology of Health \& Illness. 2012;34(8):1184-1198. doi:10.1111/i.1467-9566.201 2.01466.X

14. Prague mayor thanks Taiwan for sharing COVID-19 response materials. Taiwan News. March 2020. https://www.taiwannews.com.tw/en/news/3892 688. Accessed April 30, 2020.

15. Jefferson T, Del Mar CB, Dooley L, et al. Physical interventions to interrupt or reduce the spread of respiratory viruses. Cochrane Acute Respiratory Infections Group, ed. Cochrane Database of Systematic Reviews. 2011;(7):CD006207. doi:10.1002/ 14651858.cd006207.pub4

16. Cowling BJ, Ali ST, Ng TWY, et al. Impact assessment of non-pharmaceutical interventions against coronavirus disease 2019 and influenza in Hong Kong: An observational study. The Lancet Public Health. 2020;5(5):e279-e288. doi:10.1016/s246 8-2667(20)30090-6

17. Leung NHL, Chu DKW, Shiu EYC, et al. Respiratory virus shedding in exhaled breath and efficacy of facemasks. Nat Med. 2020;26(5):676-680. doi:10.103 8/s41591-020-0843-2

18. Kwok YLA, Gralton J, McLaws M-L. Face touching: A frequent habit that has implications for hand hygiene. American Journal of Infection Control. 2015;43(2):112-114. doi:10.1016/j.ajic.2014.10.015

19. MacIntyre CR, Seale H, Dung TC, et al. A cluster randomised trial of cloth masks compared with medical masks in healthcare workers. BMJ Open. 2015;5(4):e006577-e006577. doi:10.1136/bmjopen-20 $\underline{14-006577}$ 
20. Arden K, Johnson G, Knibbs L, Mackay I. Flight of the aerosol, understanding what we mean when we discuss airborne virus infection risk. https://virologyd ownunder.com/flight-of-the-aerosol/. Accessed March 4, 2020.

21. Ting V. To mask or not to mask: WHO makes Uturn while US, Singapore abandon pandemic advice and tell citizens to start wearing masks. South China Morning Post. https://www.scmp.com/news/hong-ko ng/health-environment/article/3078437/mask-or-no t-mask-who-makes-u-turn-while-us. Published April 4, 2020. Accessed April 30, 2020.

22. Lee HY. Tech experts helped make Taiwan's mask rationing system a success. Focus Taiwan. February 2020. https://focustaiwan.tw/society/202002280019. Accessed March 8, 2020.

23. University of Hong Kong Shenzhen Hospital experts devise do-it-yourself facemasks to help people battle coronavirus. South China Morning Post. https://www.youtube.com/watch?v=aNjpH5lBZ8w. Published February 14, 2020. Accessed March 8, 2020.

24. South Korea PM encourages people to wear reusable cotton masks. Arirang News. https://www.yo utube.com/watch?v=afSnIl8jM7c. Published March 7, 2020. Accessed March 8, 2020.

25 . Kyodo. Japan to give two masks each to 50 million households to fight virus. Japan Times. https://www.j apantimes.co.jp/news/2020/04/02/national/japanesegovernment-distribute-two-masks-per-household-ab e/\#.XqU_cGgzY7E. Published April 2, 2020. Accessed April 26, 2020.

26. van der Sande M, Teunis P, Sabel R. Professional and Home-Made Face Masks Reduce Exposure to Respiratory Infections among the General Population. Pai M, ed. PLoS ONE. 2008;3(7):e2618. doi:10.1371/jo urnal.pone.0002618

27. Davies A, Thompson K-A, Giri K, Kafatos G, Walker J, Bennett A. Testing the efficacy of homemade masks: Would they protect in an influenza pandemic? Disaster med public health prep. 2013;7(4):413-418. doi:10.1017/dmp.2013.43
28. Griffiths J. Asia may have been right about coronavirus and facemasks, and the rest of the world is coming around. CNN News. https://edition.cnn.co

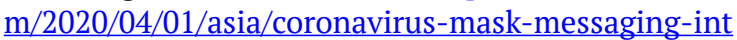
l-hnk/index.html. Published April 23, 2020. Accessed April 24, 2020.

29. Vipond J. The case for mandatory mask wearing in Canada. Macleans. April 2020. https://www.maclean s.ca/society/health/the-case-for-mandatory-mask-we aring-in-canada/?fbclid=IwAR1OIacnLrif0-PBqMl29o MycAfweAIj_XibllG3zoqp7iAxoi761Ss7woA. Accessed April 24, 2020.

30. Marlow M, Hu B. Hong Kong expats point fingers over who's spreading coronavirus. Bloomberg. March 2020. https://www.bloomberg.com/news/articles/202 0-03-23/hong-kong-expats-point-fingers-over-whos-spreading-coronavirus. Accessed April 30, 2020.

31. Divisions among Hong Kong expats over virus response. AFP. https://www.france24.com/en/202003 23-divisions-among-hong-kong-expats-over-virus-re sponse. Published March 23, 2020. Accessed April 30, 2020.

32. Health minister apologises for anti-Western slurs. Bangkok Post. https://www.bangkokpost.com/thailan d/general/1852949/health-minister-apologises-for-an ti-Western-slurs. Published February 8, 2020. Accessed April 30, 2020.

33. Czechs resort to making DIY facemasks in face of their shortage. Radio Prague International. https://w ww.radio.cz/en/section/curraffrs/czechs-resort-to-ma king-diy-facemasks-in-face-of-their-shortage. Published March 17, 2020. Accessed March 23, 2020.

34. Calman KC. The Potential for Health. Oxford University Press; 1998. doi:10.1093/acprof:oso/97801 92629449.001.0001 